\title{
JURISPRUDENCIA AMBIENTAL EN GALICIA \\ (SEGUNDO SEMESTRE 2017)
}

María del Carmen Rodríguez Martín-Retortillo

Profesora interina e investigadora del Área de Derecho Administrativo

Universidade da Coruña 
Sumario: 1. Introducción. 2. Cuestiones controvertidas en torno a la Autorización Ambiental Integrada a propósito de la sentencia 347/2017, de 20 de julio (Sección Segunda de la Sala de lo ContenciosoAdministrativo del Tribunal Superior de Justicia de Galicia). 3.Análisis de la sentencia 388/2017, de 21 de septiembre, de la Sección Segunda de la Sala de lo Contencioso-Administrativo del Tribunal Superior de Justicia de Galicia. 4. Estudio de la contaminación acústica al hilo de las Sentencias 311/2017, de 7 de junio, de la Sección Tercera de la Sala de lo Contencioso-Administrativo del Tribunal Superior de Justicia de Galicia y 375/2017, de 21 de septiembre, de la Sección Segunda de la Sala de lo ContenciosoAdministrativo del Tribunal Superior de Justicia de Galicia. 5. Aspectos relacionados con la Disposición transitoria primera de la Ley 2/2013 a la luz de la sentencia 289/2017, de 15 de junio, de la Sección Segunda de la Sala de lo Contencioso-administrativo del Tribunal Superior de Justicia de Galicia.

\section{Introducción}

La presente crónica se ha sistematizado en 4 apartados, donde se estudian distintos pronunciamientos del Tribunal Superior de Justicia de Galicia en las siguientes materias:

- Cuestiones controvertidas en torno a la Autorización Ambiental Integrada a propósito de la sentencia 347/2017, de 20 de julio (Sección Segunda de la Sala de lo Contencioso-Administrativo del Tribunal Superior de Justicia de Galicia).

- Análisis de la sentencia 388/2017, de 21 de septiembre, de la Sección Segunda de la Sala de lo Contencioso-Administrativo del Tribunal Superior de Justicia de Galicia.

- Estudio de la contaminación acústica al hilo de las sentencias 311/2017, de 7 de junio (Sección Tercera) y 375/2017, de 21 de septiembre (Sección Segunda) de la Sala de lo Contencioso-Administrativo del Tribunal Superior de Justicia de Galicia.

- Aspectos relacionados con la Disposición transitoria primera de la Ley 2/2013 a la luz de la sentencia 289/2017, de 15 de junio, de la Sección Segunda de la Sala de lo Contencioso-administrativo del Tribunal Superior de Justicia de Galicia.

\section{Cuestiones controvertidas en torno a la autorización ambiental integrada} a propósito de la Sentencia 347/2017, de 20 de julio (Sección Segunda de la Sala de lo Contencioso - Administrativo del Tribunal Superior de Justicia de Galicia).

La primera sentencia objeto de análisis es la 347/2017, de 20 de julio, de la Sección Segunda de la Sala de lo Contencioso-Administrativo del Tribunal Superior de Justicia de Galicia. 
Dicho pronunciamiento resuelve el recurso interpuesto por la Empresa "A", contra la Resolución de 22 de julio de 2015 dictada por el Secretario Xeral Técnico de la Consellería de Medio Ambiente, Territorio e Infraestructuras de la Xunta de Galicia, por la que se declara de oficio la nulidad de pleno derecho de la Resolución de 16 de mayo de 2013 de la Secretaría Xeral de Calidade e Avaliación Ambiental por la cual se renueva la autorización ambiental integrada otorgada a la mencionada empresa para una planta de elaboración de harinas y aceites de pescado situada en el Ayuntamiento de Redondela (Pontevedra), así como, por vía de ampliación, contra la resolución de la Secretaría xeral técnica de la citada Consellería de 8 de enero de 2016 desestimatoria del recurso potestativo de reposición interpuesto contra la medida provisional de parada inmediata de la instalación y clausura temporal total de sus instalaciones por carecer de la Autorización Ambiental Integrada.

En su Fundamento de Derecho Segundo recuerda que en el Suplico de la demanda se insta que se acuerde la estimación del recurso y se declare:

a) la nulidad de la Resolución de 22 de julio de 2015

b) la nulidad de la Resolución de 8 de enero de 2016 , con imposición de las costas procesales.

Por lo que respecta a la primera, la recurrente alega lo siguiente (Fundamento de Derecho Tercero):

1) La caducidad del procedimiento administrativo (motivo rechazado por la Sala con los argumentos que desarrolla en el Fundamento de Derecho Cuarto).

2) La ausencia de la causa de nulidad invocada como fundamento para iniciar la revisión de oficio y declarar la nulidad del acuerdo de 22 de julio de 2015.

3) Que la renovación de la Autorización Ambiental Integrada es un procedimiento autónomo, motivo por el cual la anulación de la Autorización Ambiental Integrada de 28 de abril de 2008 no determina automáticamente la nulidad de la Autorización Ambiental Integrada de 16 de mayo de 2013. 
En lo referente a la orden de medida provisional de parada inmediata y clausura temporal total, la parte actora expone que:

1) No ha sido requerida con carácter formal para cesar la actividad, y aunque fuese requerida, el hecho de ser titular de la licencia de actividad para industria reductora de pescado le posibilita el mantenimiento de la actividad e impide la adopción de la medida provisional que es objeto de recurso.

2) No se dan los requisitos exigidos legalmente para adoptar la medida provisional de parada inmediata de la instalación y clausura temporal total.

3) La omisión del trámite de audiencia conlleva la nulidad de pleno derecho del acuerdo de parada inmediata de la instalación y clausura temporal total.

En su Fundamento de Derecho Quinto la Sentencia enfatiza que:

"En sentencia de esta Sala de 15 de diciembre de 2011, que devino firme, mediante sentencia del Tribunal Supremo de 27 de junio de 2014, se desestimó el recurso de casación interpuesto contra aquella de 15 de diciembre de 2011 se alcanzó el siguiente Fallo: "Estimamos el recurso contencioso- administrativo interpuesto (...) contra las desestimaciones presuntas por la Consellería de Medio Ambiente e Desenvolvemento Sostible de los recursos de alzada interpuestos contra las Resoluciones de 28-04-2008 y 15-12-2008 de la Dirección General de Calidade e Avaliación Ambiental por las que, respectivamente, se otorgó Autorización Ambiental Integrada a una Planta de elaboración de fariñas e aceites de peixe, situada en Redondela, (...), y se actualizó dicha Autorización, y anulamos dichas resoluciones por ser contrarias a derecho".".

A continuación, añade que:

"También cabe significar que si se entiende que la desaparición de la AAl de 2008 por anulación judicial provoca necesaria y automáticamente la de su renovación de 2013, ello justificaría la aplicación del artículo 62.1.f) de la Ley 30/92 ante la ausencia de un requisito esencial para el otorgamiento de la revisión, situación esta última que también se produciría si se constata la 
emisión, en el expediente de renovación, de informe municipal negativo sobre compatibilidad del proyecto con el planeamiento urbanístico, que necesariamente llevaría a la aplicación de lo establecido en el artículo 15 de la Ley $16 / 2002$, de 1 de julio, de prevención y control integrados de la contaminación, sobre fin del procedimiento y archivo de las actuaciones mediante resolución motivada. Ahora bien, en lo que atañe a la cuestión sobre "independencia" o mayor o menor autonomía del procedimiento de renovación de la originaria AAI, y reconociendo la razonable aparición de cierto grado de duda al respecto, es de apuntar que la regulación contenida en el artículo 25 de la Ley 16/2002, de 1 de julio y en el artículo 7 del Reglamento para el desarrollo y ejecución de dicha Ley 16/2002, aprobado por el Real Decreto 509/2007, de 20 de abril, lleva a considerar que la decisión no debe apoyarse en exclusiva en una valoración semántica sino en el verdadero significado del expediente de renovación. Hay que tener en cuenta que la renovación, que opera cuando ya ha sido agotado el plazo fijado para la originaria AAI, tiene establecido un previo procedimiento en el que se exige "en todo caso", la inclusión, "al menos", de "los trámites de información pública, informes del ayuntamiento y del organismo de cuenca y audiencia, contemplados en el capítulo II del título III de la Ley 16/2002", así como " la documentación relativa a hechos, situaciones y demás circunstancias y características técnicas de la instalación, del proceso productivo y del lugar de emplazamiento, que no hubiera sido ya aportada a la autoridad competente con motivo de la solicitud de autorización original o durante el período de validez de la misma". Puede entenderse que el mantenimiento, conservación y virtualidad de documentación aportada con la solicitud de autorización original o durante el periodo de validez de la misma, responde a la idea de racionalización o simplificación burocrática- administrativa, y que el conjunto de aportaciones y actuaciones que deben residenciarse en sede del expediente de renovación de la $\mathrm{AAl}$, revelan que la naturaleza, sentido y alcance de esta última, responden a un grado de autonomía que, al menos, permite excluir un carácter automático e inexorable de la vinculación entre la desaparición de la AAl original y la de la renovación alcanzada, siendo teóricamente posible que ésta última y por el período que le corresponde, hubiera sido otorgada sin incurrir en defectos que hayan afectado a la autorización original y superándolos adecuadamente. En este punto, es de recordar que en la impugnada resolución de revisión, se destaca que en el expediente de renovación de la $\mathrm{AAl}$ se incurrió en el mismo defecto examinado en las sentencias antes mencionadas y que llevó a la anulación de la AAl original, como 
es el relativo a la indebida preterición de los efectos que el artículo 15 Ley 16/2002, de 1 de julio aparenta vincular a la emisión de informe municipal negativo sobre la compatibilidad urbanística".

Por lo que respecta a la impugnación formulada por vía de ampliación, la decisión de parada de la instalación y clausura temporal total, se adopta como medida provisional en el seno de expediente sancionador incoado encontrando acomodo, según señala esta sentencia en su Fundamento de Derecho Sexto, en:

- el Artículo 72 de la Ley 30/92

- el Artículo 136 de la Ley 30/92

- el Artículo 34 de la Ley 16/2002, de 1 de julio, de prevención y control integrados de la contaminación

- el Artículo 25 del reglamento aprobado por R.D. 815/2013, de 18 de octubre.

Aclara además que "es preciso indicar, sin mayor dilación, que anulada en esta sentencia la resolución de 22 de julio de 2015, sobre nulidad de pleno derecho de la resolución de 16 de mayo de 2013 sobre renovación de la AAI, deviene obligada la anulación de la resolución de 8 de enero de 2016, en cuanto que dejada sin efecto la de 22 de julio de 2015, no es posible reconocer las consecuencias que fueran conectables a la nulidad e inexistencia de la resolución de renovación de la AAl".

El fallo se resume en los siguientes puntos:

1) Estimar el recurso.

2) Anular las resoluciones de 22 de julio de 2015, 23 de noviembre de 2015 y 8 de enero de 2016 por ser contrarias a Derecho.

3) No realizar imposición de costas, ya que como indica el Fundamento Jurídico Séptimo de la sentencia se aprecian dudas razonables en la interpretación de la normativa aplicable al mencionado caso.

3. Análisis de la Sentencia 388/2017, de 21 de septiembre, de la Sección Segunda de la Sala de lo Contencioso - Administrativo del Tribunal Superior de Justicia de Galicia. 
La segunda sentencia estudiada es la 388/2017, de 21 de septiembre, de la Sección Segunda de la Sala de lo Contencioso-Administrativo del Tribunal Superior de Justicia de Galicia, que resuelve el recurso interpuesto por la Empresa "T" contra la sentencia del Juzgado Contencioso-administrativo n-1 de Santiago de Compostela, siendo parte apelada el Concello de Santiago de Compostela.

El Antecedente de Hecho Primero recuerda que el Juzgado de lo Contencioso Administrativo, $\mathrm{n}$ 1ㅜ de Santiago de Compostela dictó sentencia el 31 de marzo de 2017, desestimatoria del recurso interpuesto frente al Decreto de 16 de julio de 2015 que rechaza el recurso de reposición contra el Decreto de 16 de julio de 2014 que ordena la retirada y el cese del uso de la antena de telefonía móvil instalada en una calle de Santiago.

El Fundamento de Derecho Segundo de la sentencia 388/2017 indica que el Decreto de 16 de julio de 2014 acordaba lo siguiente:

1ํ) La ejecución forzosa del Decreto de 26 de marzo de 2007 que ordenaba a la Empresa "T" la retirada y el cese en el uso de la antena instalada en la mencionada calle.

$2^{\circ}$ ) Imponer una multa coercitiva de 1.500 euros.

La parte actora esgrime los siguientes motivos impugnatorios:

1) Que resulta de aplicación la Ley 9/2014, de 9 de mayo, General de Telecomunicaciones (y no la Ley 32/2003).

2) Impugna indirectamente el artículo 5.2.f) de la Ordenanza Municipal, que no permite instalar antenas de telefonía móvil en edificios de menos de 10 metros, dado que se encuentra desfasado e incumple lo estipulado por el Artículo 34 de la Ley 9/2014.

3) Que el órgano judicial no ha valorado adecuadamente la prueba practicada y que su pronunciamiento acerca del cese de actividad resulta contrario a Derecho.

Por su parte, el Ayuntamiento de Santiago de Compostela: 
a) Se opone al considerar que el recurso es inadmisible por razón de la cuantía (pretensión rechazada por la Sala en su Fundamento de Derecho Tercero cuando señala que "En la instancia se impugnaba no solo el decreto de 16.7.2014 que ordena la retirada y cese del uso de la antena de telefonía móvil instalada (...), sino también la Ordenanza Municipal del Ayuntamiento de Santiago de Compostela reguladora de las condiciones urbanísticas para la instalación y funcionamiento de elementos y equipos utilizados en la prestación de servicios de radiocomunicación, aprobada por el Pleno en sesión de 30 de marzo de 2006 impugnada de modo indirecto", con lo que ha de entenderse la cuantía indeterminada)

b) Defiende la conformidad a Derecho de la sentencia objeto de apelación.

En su Fundamento de Derecho Cuarto la Sala se refiere al primer motivo alegado por la recurrente relativo a la aplicación de la Ley 9/2014 en vez de la Ley $32 / 2003$, recordando que la actora pretende "a la vista de la cronología temporal una aplicación retroactiva de la norma, hasta el punto de solicitar la nulidad de una Ordenanza Municipal aprobada bajo la vigencia de la Ley anterior de 2003". A continuación, argumenta por qué debe ser rechazado y para ello se basa en 2 motivos:

1) Por la aplicación de la D.T.7ª) de la Ley 9/2014 (que indica que "Los procedimientos iniciados con anterioridad a la entrada en vigor de la presente Ley, y que tengan por finalidad la obtención de licencias y autorizaciones de obra, instalaciones, de funcionamiento o de actividad, o de carácter medioambiental u otras de clase similar o análogas que fuesen precisas con arreglo a la normativa anterior, se tramitaran y resolverán por la normativa vigente en el momento de la presentación de la solicitud") y el principio de retroactividad mínima.

2) En que la parte actora presentó su escrito de Comunicación Previa de inicio de actividad el 19 de noviembre de 2013, que "sustituye según la nueva normativa a la solicitud de una licencia, por lo que no cabe duda la solicitud se presentó bajo la vigencia de la Ley General de Telecomunicaciones del 2003 aplicable a todo procedimiento iniciado bajo su vigencia. Fue con posterioridad a esa fecha que entró en vigor la Ley 9/2014, de 9 de mayo, General de Telecomunicaciones, norma que no prevé su aplicación retroactiva”. 
En esta misma línea, recalca que se debe rechazar la petición de la recurrente relativa a que el procedimiento se rija por la normativa vigente en la actualidad, ya que en otro caso se vulnerarían el principio de seguridad jurídica y el de irretroactividad de las leyes, teniendo en cuenta además el carácter restrictivo de la interpretación de las normas de Derecho transitorio.

En su Fundamento de Derecho Quinto aborda la cuestión relativa a la impugnación de la Ordenanza y para ello comienza aludiendo a la sentencia dictada por esta sala del TSJ de Galicia de 8 de abril de 2009 en el recurso contra el acuerdo del Ayuntamiento de Santiago de Compostela, donde resultó objeto de impugnación la Ordenanza municipal del Ayuntamiento de Santiago de Compostela reguladora de las condiciones urbanísticas para la instalación y funcionamiento de elementos y equipos utilizados en la prestación de servicios de radiocomunicación, aprobada por el Pleno en sesión de 30 de marzo de 2006.

En la mencionada sentencia hacía referencia a sendos pronunciamientos del Tribunal Supremo de 18 de junio de 2001 y 15 de diciembre de 2003 sobre la capacidad de los Ayuntamientos para, en el planeamiento urbanístico, establecer condiciones para la instalación de antenas y redes de telecomunicaciones, y contemplar exigencias y requisitos para efectuar las correspondientes instalaciones en ordenanzas o reglamentos, indicando lo siguiente:

“1.- Que La competencia estatal en relación con las telecomunicaciones no excluye la del correspondiente municipio para atender a los intereses derivados de su competencia en materia urbanística, con arreglo a la legislación aplicable, incluyendo los aspectos de estética y seguridad de las edificaciones y medioambientales.

2.- Que Por consiguiente, los Ayuntamientos pueden, en el planeamiento urbanístico, establecer condiciones para la instalación de antenas y redes de telecomunicaciones, y contemplar exigencias y requisitos para realizar las correspondientes instalaciones en ordenanzas o reglamentos relativas a obras e instalaciones en la vía pública o de calas y canalizaciones o instalaciones en edificios (art. 4.1 a) LRBRL y 5 RSCEL), (...)

4.- Que por ello puede resultar útil, de acuerdo con la doctrina del Tribunal Constitucional y la jurisprudencia de esta Sala, el examen de los preceptos cuestionados desde las perspectivas de los parámetros que sirven para 
determinar la existencia de proporcionalidad; esto es, la idoneidad, utilidad y correspondencia intrínseca de la entidad de la limitación resultante para el derecho y del interés público que se intenta preservar (...) y que La autonomía municipal es, en efecto, una garantía institucional reconocida por la Constitución para la gestión de sus intereses (artículos 137 y 140 de la Constitución y hoy asumida en los compromisos internacionales por el Reino de España (...), concluyendo que los Ayuntamientos pueden establecer las condiciones técnicas y jurídicas relativas a cómo ha de llevarse a cabo la utilización del dominio público que requiera el establecimiento o la ampliación de las instalaciones del concesionario u operador de servicios de telecomunicaciones, en su término municipal, utilizando el vuelo o el subsuelo de sus calles y que Este principio es plenamente aplicable a las instalaciones por parte de los operadores (sujetos a la sazón al régimen de concesión) que puedan afectar en cualquier modo a los intereses que la Corporación municipal está obligada a salvaguardar en el orden urbanístico, incluyendo la estética y seguridad de las edificaciones y sus repercusiones medioambientales, derivadas de los riesgos de deterioro del medio ambiente urbano que las mismas puedan originar y que Las expresadas instalaciones por parte de las empresas de servicios aconsejan una regulación municipal para evitar la saturación, el desorden y el menoscabo del patrimonio histórico y del medio ambiente urbano que puede producirse, por lo que no es posible negar a los Ayuntamientos competencia para establecer la regulación pertinente.(...)".

A su vez, en su Fundamento Jurídico Séptimo se refería al Artículo 5.2.f) cuya impugnación indirecta se ha realizado en este procedimiento, señalando lo siguiente:

"El artículo 5.2, apartado f), al prever, que En edificios de menos de diez metros de altura no se permitirá la instalación de estaciones base de telefonía móvil, al igual que el artículo 7 al indicar que En los edificios y zonas catalogadas se prohíben con carácter general estas instalaciones, a no ser que la solución propuesta suponga la anulación del impacto visual desfavorable y así lo dictaminen los órganos municipales competentes en materia de patrimonio histórico y cuando así se precise de acuerdo con la normativa sectorial aplicable a los órganos e instituciones competentes en materia de protección del patrimonio histórico-artístico, natural y de la estética urbana, deben comprenderse en el marco de la coordinación. Responden al igual que el artículo 2.3 y 3.1 a razones urbanísticas, medioambientales y paisajísticas, así como a 
motivos histórico-patrimoniales, por los que los Ayuntamientos deben velar. Y lo mismo procede indicar con relación a las previsiones del artículo 8, relativo a las condiciones de las instalaciones en fachadas de edificios; a las del artículo 11, relativo a las instalaciones en zonas de viviendas unifamiliares y núcleos rurales; a las del artículo 12, referido a las instalaciones en zona rural y a las del artículo 13, concretamente a las instalaciones en polígonos industriales. La lectura de dichos preceptos no permite entender la razón de su impugnación, sólo puede explicarse desde una inaceptable negativa de las competencias propias de la administración local. Y no otra cosa puede decirse con respecto a la impugnación del artículo 9.1, relativo a la autorización de la localización".

Por ello la Sala se remite a la mencionada sentencia desestimando el aludido motivo de impugnación.

El Fundamento de Derecho Sexto comienza diciendo que la resolución recurrida expresa que el Decreto de 23 de marzo de 2007 que ordenaba la retirada y cese de la estación de telefonía móvil es firme en vía administrativa y jurisdiccional y que el Juzgado Contencioso-Administrativo nำ1 de Santiago de Compostela dictó sentencia, que es firme al ser confirmada por el Tribunal Superior de Justicia de Galicia.

Termina afirmando que en el proceso de legalización se ha informado que no se cumplen las condiciones urbanísticas y que se vulnera el Artículo 5 de la Ordenanza Municipal, enfatizando que:

"Ninguno de estos argumentos se rebate por parte de la parte apelante; por lo tanto, no constando la legalización de la estación de telefonía móvil cuya retirada y cese de uso ha sido acordada, la consecuencia no es otra que la necesidad de desmontar y retirar la citada estación de su ubicación actual, procediendo así la desestimación del recurso de apelación interpuesto contra la sentencia que así lo decide, que debe ser confirmada".

Finalmente, en su Fundamento de Derecho Séptimo postula que:

"La completa desestimación del recurso impone la condena a la parte actora al pago de las costas, a tenor de lo dispuesto en el artículo 139.1 LJCA, en la redacción dada por la Ley 37/2011 (artículo 139.2 de la Ley jurisdiccional) cuantía 1.000 euros". 


\section{Estudio de la contaminación acústica al hilo de las sentencias $311 / 2017$,} de 7 de junio, de la Sección Tercera de la Sala de lo ContenciosoAdministrativo del Tribunal Superior de Justicia de Galicia y 375/2017, de 21 de septiembre, de la Sección Segunda de la Sala de lo ContenciosoAdministrativo del Tribunal Superior de Justicia de Galicia.

La tercera sentencia objeto de estudio es la 311/2017, de 7 de junio, de la Sección Tercera de la Sala de lo Contencioso-Administrativo del Tribunal Superior de Justicia de Galicia, que resuelve el recurso interpuesto contra la Conselleria De Medio Ambiente, Territorio e Infraestructuras (Agencia Gallega de Infraestructuras).

El Razonamiento Jurídico Segundo recuerda que:

"El actor impugna la desestimación por silencio administrativo de una reclamación por responsabilidad patrimonial por daños formulada primero contra la Axencia Galega de Infraestructuras, ampliada después a la Resolución expresa, de fecha 7 de enero de 2014, del Secretario Xeral Técnico de la Consellería de Medio Ambiente, Territorial e Infraestructuras, desestimatoria. La primera se fundamentaba en que, con ocasión de las obras de construcción de la Autopista del Valle Minor, se habían producido toda un serie de daños continuados en la vivienda del actor situada en Donas, (...) en el término municipal de Gondomar, en unos terrenos contiguos en la parte inferior a la propia zona de paso de la mencionada vía, y en la segunda se había ampliado la petición indemnizatoria a otros daños sobrevenidos con posterioridad y al resarcimiento de la fuerte contaminación acústica que el tránsito de vehículos por la autopista, prácticamente construida encima de un lateral de la vivienda, había supuesto para la tranquilidad y sosiego de sus moradores".

Continúa expresando que "nunca sería aceptable que el uso de una infraestructura de tal magnitud e importancia, como la de autos, pudiese suponer una inmisión acústica y sonora de tal importancia y fuera de los límites legales en el ámbito de la casa situada mismo a su lado y en perjuicio de la salud y tranquilidad de sus moradores. En cuanto a todo ello, la Sala ha analizado a fondo todas las pruebas de que dispuso en el expediente y en las actuaciones, y, valorando todo ello según las reglas de la sana crítica, llega a la conclusión, por las consideraciones que pasan a exponerse, de se cumplen los requisitos 
precisos para que prospere en gran parte la reclamación ejercitada en el concepto ya dicho".

El Razonamiento Jurídico Tercero insiste en las numerosas reclamaciones de particulares afectados ya desde el inicio de las obras de construcción de la autopista, ya que, aunque el proyecto optó por las zonas más abiertas y menos pobladas para su paso, en ciertos lugares tuvo que acercarla a espacios urbanos consolidados por la edificación, con el riesgo de dañar construcciones o de originar contaminación acústica en las viviendas más cercanas.

Así, invoca precedentes de esta Sala (Sentencias de la Sección $2^{a}$ de 23 de octubre de 2003 y de 24 de junio de 2004) al respecto de estimaciones parciales importantes de reclamaciones por daños a causa de su construcción y de compensaciones por la fuerte contaminación acústica que padecieron algunas de las viviendas:

- La primera reconoce una adecuada relación causal entre las obras y los daños materiales sufridos por la vivienda y recuerda que los artículos 45, 15 y 18 de la Constitución protegen derechos fundamentales relacionados con el medio ambiente, la calidad de vida, la integridad física y moral, y la inviolabilidad del domicilio, "de lo que puede deducirse que una exposición continuada a niveles intensos de ruidos en el mismo, además de ser contrario a un medio ambiente adecuado y al derecho a la calidad de vida, puede poner en peligro la salud de las personas, ya que cuando los niveles de saturación acústica que deba soportar una persona, a consecuencia de una acción y omisión de los poderes públicos, rebasen el umbral a partir del cual se ponga en peligro grave e inmediato la salud, podrá quedar afectado el derecho garantizado por el art. 15 de la C.E., por lo que estos problemas han de plantearse sobre la perspectiva de entidad e importancia del nivel de ruidos, tema sobre el que se insistirá más adelante en este concreto recurso".

- La segunda sigue la misma línea afirmando que "la propiedad de la parte recurrente resulta afectada, en razón de su proximidad a esa misma autopista, en un grado claramente superior al que supone para las propiedades cercanas, por lo general, la construcción de una nueva vía, ya que las molestias que determina la situación que aquí se enjuicia entrañan un sacrificio superior al 
normal, lo que permite considerar que se ha causado una lesión antijurídica, que, conforme a lo dispuesto en el art. 139 de la Ley 30/92, tiene que ser indemnizada, tal como había entendido ya la jurisprudencia (...) (STS 7-5- 2002 y 10-12-1982, entre otras)".

El Razonamiento Jurídico Cuarto hace hincapié en que ya desde el principio el actor formuló numerosas quejas y reclamaciones a la Administración demandada, la que adoptó una actitud ambigua, reconociendo la existencia de algunos daños pero en una cuantía mucho menor de la solicitada, y negando después la responsabilidad en lo concerniente a los ruidos, "cuando, pasado un tiempo sin solución a ninguno de estos problemas, se hizo una ampliación de la reclamación por daños y perjuicio más extensa y concreta, con base en dos informes periciales de parte relativos a esos dos conceptos indemnizatorios en discusión, ratificados después en juicio con todas las garantías de contradicción”. Continúa explicando que:

"El informe sobre los daños, prestado por un arquitecto técnico, pone de manifiesto que, para la ejecución del vial había sido precisa la realización de un importante puente con el fin de salvar los desniveles existentes entre el terreno natural y los aterramientos anteriores para suavizar la pendiente, cuya ejecución se realizó prácticamente en la vertical de la fachada lateral de la casa y para su sujeción fueron realizados unos importantes pilares de apoyo frente a la vivienda, apoyados sobre zapatas de hormigón enterradas en el terreno, lo que determinó la realización de importantes desmontes en la zona próxima, todo lo cual dañó seriamente la vivienda propiedad del actor de la manera que se indica en el informe, en la que se produjeron los daños estructurales y grietas que se citan, tanto en la cubierta como en las paredes, tal como se explica con todo detalle en las fotografías incorporadas al expediente, todo lo cual se valoró económicamente, de acuerdo con los cálculos sobre las diferentes partidas expuesta, en la suma de 6.337.718 pts (38.090,45 euros), valoración que la Sala considera correcta en todos sus apartados, por lo que esta pretensión ha de ser estimada (...)".

Añade que resulta más problemática la determinación de la indemnización por los ruidos y contaminación acústica, ya que la Xunta sostuvo que los daños acústicos por el uso de la autopista no eran superiores a los normales y no 
superaban los niveles acústicos máximos permitidos, lo que en ningún caso sería indemnizable, interpretando que el resultado del estudio llevado a cabo avalaba su tesis al no superarse en las pruebas los niveles acústicos mínimos exigidos por la Ley 7/97, de Protección contra la contaminación acústica, sin embargo uno de los peritos dictaminó que los niveles de ruido no se situaban por debajo de los máximos permitidos, puesto que en franjas horarias concretas sí se superaban y afectaban al uso de la vivienda, que debía ser objeto de un tratamiento de aislamiento acústico, y el perito idóneo en esta problemática se ratificó en el informe técnico acústico incorporado al expediente. Por tanto, afirma que "de todo lo cual puede deducirse que la contaminación acústica entraba, aunque de una manera no muy intensa, dentro de los límites prohibidos, y, por tanto, se cumplían las condiciones mínimas para su adecuado resarcimiento económico, cuya determinación concreta ya se reconoce en la demanda que puede estar influida por ciertos criterios subjetivos, pudiendo en cierto modo dejarse la fijación de su cuantía al criterio del juzgador".

De conformidad con lo expuesto, "se fija prudencialmente una indemnización por este concepto de 25.000 euros, en el que se comprendería el daño moral derivado de la inmisión de los ruidos y el añadido de los trabajos mínimamente necesarios para la mejora en la casa de las condiciones acústicas, por lo que también se estima en parte esta otra pretensión. Resulta así una indemnización total, por todos los conceptos, de 63.090,45 euros, que ya se toma como deuda valor determinada en la sentencia, y que, por lo tanto, no devenga interés alguno hasta este mismo momento de su determinación definitiva en esta resolución judicial".

Finalmente, el Razonamiento Jurídico Quinto concluye que por todo lo expuesto, se estima en parte el recurso presentado, sin especial mención en cuanto al pago de las costas procesales.

La cuarta sentencia a tratar es la 375/2017, de 21 de septiembre, de la Sección Segunda de la Sala de lo Contencioso-administrativo del Tribunal Superior de Justicia de Galicia, que resuelve el recurso interpuesto por el Ayuntamiento de Cambados contra la sentencia del Juzgado de lo Contencioso-administrativo $\mathrm{n} \times 1$ de Pontevedra, dictada en el Procedimiento especial de protección de los 
derechos fundamentales de la persona $\mathrm{n}$-269/2016, siendo parte apelada D. "H" y D. "l”, con intervención del Ministerio Fiscal.

El Antecedente de Hecho Primero recuerda que por el Juzgado de lo Contencioso-administrativo ํำ1 de Pontevedra el 14 de marzo de 2017 se dictó sentencia en procedimiento especial de protección de los derechos fundamentales de la persona, conteniendo la siguiente parte dispositiva:

"Estimo el recurso contencioso-administrativo, tramitado como procedimiento especial de protección de los derechos fundamentales de la persona ㄲ269/2016, interpuesto (...) contra la inactividad del Ayuntamiento de Cambados ante el escrito presentado (...) en fecha 6 de julio de 2016 por el que se le requería a fin de que de modo inmediato procediese a decretar el cierre y cese de actividad del local Bar (...), situado en el bajo del edificio de la comunidad en que tienen sus viviendas, declarando que ha existido inactividad del Ayuntamiento de Cambados y vulneración de derecho fundamental y, ordenando al Ayuntamiento de Cambados que proceda, de modo inmediato, a decretar el cierre y el cese de la actividad del local Bar (...) y a incoar el correspondiente expediente de reposición de la legalidad urbanística, y todo ello, con expresa imposición de costas a la Administración demandada con un límite de 700 euros (gastos de defensa y representación)".

Por su parte, como expone el Antecedente de Hecho Segundo, el Ayuntamiento de Cambados interpuso recurso de apelación contra la citada resolución judicial, solicitando que se dicte sentencia anulando la apelada, por no resultar conforme a Derecho.

El Antecedente de Hecho Tercero indica que el recurso fue admitido a trámite y se dio traslado a las demás partes, formulando oposición el Ministerio Fiscal, que interesa se desestime el recurso y se confirme íntegramente la resolución judicial que se recurre al resultar conforme a Derecho y la representación de D. "H" y D. "l", que interesa en el mismo sentido.

El Fundamento Jurídico Segundo expone que:

"En la sentencia apelada se hace referencia a que los demandantes son vecinos, y a que se trata de denuncias formuladas por tratarse de un local que funciona ilegalmente, en que se producen humos, ruidos y olores; tras las mediciones acústicas, resulta que no cumple con la normativa; y se encuentra a tratamiento 
médico algún vecino como consecuencia de ello. Se consideran vulnerados los derechos fundamentales de los artículos 15 y 18 de la CE; se hace referencia a la inviolabilidad del domicilio; y ello derivado de las quejas de los vecinos por las irregularidades e incumplimientos del local, a pesar de lo cual existió inactividad municipal, resultando de los informes técnicos obrantes en el expediente que el local no cumple las condiciones de la licencia de apertura".

La parte recurrente alude a la existencia de un procedimiento ordinario tramitado ante el Juzgado de lo Contencioso-administrativo no3 de Pontevedra, junto con la correspondiente pieza separada de medidas cautelares, donde se dictó auto de 14 de diciembre de 2016, en base al que estima que podría continuar con su actividad, teniendo en cuenta que impone la realización de determinadas comprobaciones. Continúa afirmando que:

"No obstante, lo que se aprecia es que en base al mismo se emitió informe municipal de 4 de abril de 2017 en que se dice que procede iniciar el procedimiento para el cierre del local. La parte apelante interpreta este informe con un significado contrario a su sentido, puesto que manifiesta que el concello considera que el local sí que cumple con la normativa y que en cualquier caso la subsanación de los defectos es un tema privado entre los propietarios.

Examinando el informe del arquitecto técnico municipal de 4 de abril de 2017, lo que se dice en realidad en el mismo, en síntesis, es que solo hay una cuestión insalvable, que es la inmisión de humos y olores en las viviendas por el conducto de humos y gases del local, pero que sin entrar en la cuestión referente a la competencia para su reparación, se considera que el local no puede seguir funcionando en estas condiciones por las afecciones negativas a la salubridad e higiene de las viviendas y de sus moradores, donde se produce esta inmisión. Y por ello considera que desde un punto de vista estrictamente técnico, procede el inicio de los trámites de cierre del local en tanto no se resuelva y se compruebe la estanqueidad total del conducto de evacuación de humos y gases del local".

En este Fundamento trae a colación la sentencia dictada por este Tribunal el 18 de febrero de 2016, enfatizando que "la tranquilidad nocturna, extensible a la tranquilidad de los moradores de una vivienda a lo largo del día, reviste carácter de derecho fundamental individual amparable a la luz de los arts. 10.2 y 18.1 y 2 de la Constitución española, partiendo de la doctrina contenida en la sentencia 
de fecha 16 de noviembre de 2004, del Tribunal Europeo de Derechos Humanos, donde se condenó a España por la inactividad municipal frente al ruido generado por un local de ocio, al estimarse que las molestias generadas eran incompatibles con el art. 8.1 del Texto Refundido del Convenio Europeo para la protección de los Derechos Humanos y las Libertades Fundamentales, hecho en Roma el día 4 de noviembre de 1950 y refundido ulteriormente mediante el Protocolo núm. 11 al mismo, hecho en Estrasburgo el día 11 de Mayo de 1994, ratificado por España mediante Instrumento de Ratificación de fecha 28 de noviembre de 1996 y en vigor en lo que a la misma afecta en fecha 1 de noviembre de 1998 (B.O.E. núm. 106/99), que establece que toda persona tiene derecho al respeto de su vida privada y familiar, de su domicilio y de su correspondencia, precisándose que los atentados contra el derecho al respeto del domicilio no comprenden solamente los atentados materiales o corporales, como la entrada en el domicilio de una persona no autorizada, sino también los atentados inmateriales o incorporales, tales como los ruidos, las emisiones, los olores y otras injerencias. Si los atentados son graves, pueden privar a una persona de su derecho al respeto del domicilio, puesto que aquellos le impiden disfrutar de su domicilio (...)".

Prosigue analizando la inactividad municipal, asegurando que ha supuesto una vulneración de los derechos fundamentales de los demandantes y en especial del derecho a la inviolabilidad del domicilio, como así resulta de los informes municipales, puesto que ya el informe del arquitecto municipal de 15 de febrero de 2016 indica que el local no cumple las condiciones bajo las que se otorgó la licencia de apertura y eso incide en la seguridad en caso de incendio, la seguridad de utilización, la salubridad o las condiciones acústicas y que no consta ni la incoación de expediente de reposición de la legalidad ni orden de cese cautelar de la actividad.

El titular del local, por su parte, aporta documentación para justificar la subsanación y la comunidad de vecinos aporta informe de arquitectos de donde se infiere que continúa habiendo defectos en el conducto de ventilación y campana extractora y en el aislamiento acústico. Añade este Fundamento Jurídico que: 
"El auto a que se refiere la parte apelante, dictado en incidente de medidas cautelares, es compatible con esta sentencia, además de que, en principio, se admite la existencia de las deficiencias e inactividad, y si bien y en todo caso en este momento se aporta documentación acreditativa del cierre cautelar, ello es simplemente derivado de la ejecución de la sentencia dictada en primera instancia y aquí apelada. $Y(\ldots)$, el informe del técnico municipal confirma la tesis de la sentencia apelada, al margen de a quién le corresponda la responsabilidad de los arreglos -si bien y en todo caso quien realiza la actividad que causa los perjuicios es el titular del local litigioso-“

Por todo ello el recurso de apelación resulta desestimado con imposición de las costas del recurso de apelación a quien lo interpuso, dentro del límite de 1.000 euros con relación a los honorarios del letrado de la parte apelada (tal y como se indica en el Fundamento Jurídico Tercero de la Sentencia).

\section{Aspectos relacionados con la Disposición Transitoria Primera de la Ley} 2/2013 a la luz de la Sentencia 289/2017, de 15 de junio, de la Sección Segunda de la Sala de lo Contencioso - Administrativo del Tribunal Superior de Justicia de Galicia.

La última sentencia objeto de esta crónica es la 289/2017, de 15 de junio, de la Sección Segunda de la Sala de lo Contencioso-administrativo del Tribunal Superior de Justicia de Galicia, que resuelve el recurso interpuesto por la Axencia de Protección da Legalidade Urbanística contra la sentencia dictada por el Juzgado de lo Contencioso-administrativo no3 de Pontevedra el 16 de enero de 2017, siendo parte apelada la Comunidad hereditaria de D. "S".

Tal y como relata el Antecedente de Hecho Primero, la sentencia de instancia contenía el siguiente fallo:

- La estimación del recurso contra la resolución de 9 de diciembre de 2015 del Director de la Axencia de Protección da Legalidade Urbanística (A.P.L.U.) desestimatoria del recurso de reposición formulado por "L" en calidad de representante de la comunidad hereditaria contra la resolución de 31 de agosto de 2015 del Director de la APLU que acuerda la ejecución subsidiaria de la 
resolución de 2 de julio de 2001 (sobre demolición de obras ilegales) a costa de "L" y de la mencionada comunidad hereditaria.

- La declaración de la citada resolución como contraria a Derecho

- Su revocación

- La condena en costas a cargo de la Administración demandada en cuantía que no excederá de 800 euros en lo referente a gastos de defensa y representación.

Por su parte, la Administración demandada interpuso recurso de apelación contra la citada sentencia, solicitando que se dictase por esta Sala otra que la revocase y desestimase el recurso.

En su Fundamento de Derecho Segundo indica que:

"La sentencia dictada en primera instancia acoge el recurso contenciosoadministrativo interpuesto contra las resoluciones dictadas por la Administración demandada con fechas 9 de diciembre y 31 de agosto de 2015 porque considera que el informe emitido el 25 de mayo de 2015 por la Dirección General de Sostenibilidad de la Costa y el Mar del Ministerio de Agricultura, Alimentación y Medio Ambiente no es la resolución a la que se refiere el artículo 8.3ํㅡ del Plan de inspección urbanística para el año 2015, aprobado por el Consejo Ejecutivo de la Agencia de Protección de la Legalidad Urbanística (APLU) en su reunión de 27 de enero de 2015. En lo que aquí interesa este precepto dice:

Los expedientes tramitados dentro de la zona de servidumbre de protección del dominio público marítimo terrestre que afecten a terrenos que puedan acogerse a lo establecido en la disposición transitoria primera de la Ley 2/2013, de 29 de mayo, de protección y uso sostenible del litoral, y de modificación de la Ley 22/1988, la ejecución forzosa quedará en suspenso siempre y cuando la Administración municipal acredite el cumplimento de los requisitos y que tiene solicitado el informe señalado en los apartados segundo y tercero de la citada disposición".

Recuerda que la suspensión se alzará de existir resolución definitiva y desfavorable del Ministerio de Agricultura, Alimentación y Medio Ambiente.

Asimismo, la sentencia apelada considera que para que un acto pueda calificarse como definitivo es preciso "que decida de forma definitiva, en vía administrativa, 
sin otra expresión de voluntades a mayores de la que él mismo constituya, la cuestión de fondo a resolver por la Administración Pública”.

El Fundamento de Derecho Tercero trae a colación que:

"La Disposición transitoria primera de la Ley 2/2013 establece que en plazo de dos años desde su entrada en vigor se podrá instar que el régimen previsto en la disposición transitoria tercera, apartado 3, de la Ley 22/1988, de 28 de julio, de Costas, se aplique igualmente a los núcleos o áreas que, a su entrada en vigor, no estuvieran clasificados como suelo urbano pero que, en ese momento, reunieran determinados requisitos. Para ello prevé distintas actuaciones de la Administración urbanística competente según los núcleos o áreas estén o no delimitados en el planeamiento, y en todo caso exige un informe favorable del Ministerio de Agricultura, Alimentación y Medio Ambiente, que habrá de emitirse en el plazo de 18 meses, y que se entenderá favorable si no se emite en ese plazo".

Continúa argumentando que el Artículo 8.3ํำ del Plan de inspección urbanística para 2015 se refiere a la resolución definitiva del Ministerio de Agricultura, Alimentación y Medio Ambiente, no a la resolución definitiva del procedimiento tramitado por la Administración urbanística competente, cuyo contenido viene determinado por el sentido de un informe de carácter preceptivo y vinculante. Añade que "esa resolución definitiva ya había sido dictada cuando se alzó la suspensión de la ejecución forzosa, y en consecuencia las resoluciones impugnadas son conformes a derecho".

Finalmente cabe aludir al fallo, cuyo contenido es el siguiente:

1) Estimar el recurso de apelación interpuesto por la Axencia de Protección da Legalidade Urbanística contra la sentencia de 16 de enero de 2017 por el Juzgado de lo Contencioso-administrativo nํㅜ de Pontevedra y revocarla.

2) Desestimar el recurso contencioso-administrativo interpuesto por la Comunidad hereditaria de D. "S" contra las resoluciones de 9 de diciembre 31 de agosto de 2015 de la APLU, que acuerdan la ejecución subsidiaria de la resolución de 2 de julio de 2001.

3) No hacer imposición de las costas procesales de segunda instancia, e imponer las de primera instancia, con el límite indicado en el Fundamento de Derecho Cuarto ("De acuerdo con lo dispuesto en el artículo 139.2 de la Ley jurisdiccional 
no procede hacer imposición de las costas del recurso de apelación al ser estimado; las de primera han de ser impuestas, al ser desestimado el recurso contencioso-administrativo, a quien lo interpuso (número 1 del mismo precepto), si bien con el límite de 800 euros") a la parte actora. 